\title{
Surgical treatment of primary spontaneous pneumothorax: what is better to do?
}

\author{
Dania Nachira, Elisa Meacci, Maria Teresa Congedo, Luca Pogliani, Marco Chiappetta, Maria Letizia Vita, \\ Stefano Margaritora
}

Department of General Thoracic Surgery, Fondazione Policlinico Universitario “A. Gemelli”, IRCCS, Università Cattolica del Sacro Cuore, Rome, Italy

Correspondence to: Dania Nachira, MD. Department of General Thoracic Surgery, Fondazione Policlinico Universitario “A.Gemelli”, Largo A. Gemelli, 8, 00168, Rome, Italy. Email: danynac@libero.it.

Provenance and Peer Review: This article was commissioned by the Editorial Office, Fournal of Thoracic Disease. The article did not undergo external peer review.

Comment on: Dżeljilji A, Karuś K, Kierach A, et al. Efficacy and safety of pleurectomy and wedge resection versus simple pleurectomy in patients with primary spontaneous pneumothorax. J Thorac Dis 2019;11:5502-8.

Submitted Feb 02, 2020. Accepted for publication Feb 20, 2020.

doi: $10.21037 /$ jtd.2020.03.40

View this article at: http://dx.doi.org/10.21037/jtd.2020.03.40

Primary spontaneous pneumothorax (PSP) is the most common respiratory disorder reported in young patients, with an annual incidence of $15.5-22.7 / 100,000,3-5$ times most frequent in males than in females (1).

Bullae and blebs, as only risk factors for the genesis of PSP, are demonstrated in about $20 \%$ of cases, while peripheral pleural porosity and obstruction with air trapping are supposed to be other pathogenethic mechanisms (2-4).

Till now and despite several studies and international guidelines, that often do not define surgical procedures explicitly, a significant heterogeneity can be found in the management of PSP by thoracic surgeons.

In their latest prospective experience on 73 patients affected by PSP, Dżeljilji and coworkers (5) showed how pleurectomy alone or combined with wedge resection is comparable in terms of safety and efficacy.

In group of wedge resection, a higher risk of recurrence was recorded (4 cases $v s$. 0 ). They performed wedge resection only in case of detection of blebs or air leak intraoperatively (stage III and IV of Vanderschueren's classification), according to literature suggestion, and argued that the major recurrence recorded in bullectomy cohort reflected the worst conditions of the lung parenchyma in those patients. On the other hand, the authors believed that bullectomy alone does not decrease the rate of PSP recurrence, if not associated to pleurodesis, as already proved by other studies (6-11).
In 2019, the Italian pneumothorax working group, on behalf of the Italian society of Thoracic Surgeons (SICT), made a systematic review [according to the Systematic review and Meta-analyses (PRISMA) statement] with the aim of establishing the national recommendations for the diagnosis and treatment of PSP (1). Out of 231 papers identified, 25 studies were included in qualitative synthesis for driving conclusions. Video assisted thoracic surgery (VATS) was considered the most common and preferred approach; bullectomy was strongly suggested in case of Vanderschueren's stage III and IV and in stage I might not be required. Surgical pleurodesis (pleural abrasion or pleurectomy) was recommended to limit recurrences (1).

In fact, several studies (8-11) showed how the risk of PSP recurrence can be higher after bullectomy, above all in young patients (age $<20-23$ years). The causes seem to be found in the increased risk of new blebs and bullae formation in the staple line (9), due to raise of tension during re-inflation, that leads to deformation of alveolar bronchioles near the stapler stitches (where the visceral pleura is weak), or to the volume $(>1.5 \mathrm{~g})$ of resected lung $(8,9)$.

Other studies $(8,10)$ investigated the relationship between neo-generation of bullae after bullectomy and age of patients. Young age ( $<20-23$ years) seems associated with higher risk of neogenetic bullae, probably related to variation of pressure during growth of chest cavity and 
increase of tension forces on the apex of lung and previous staple line.

This is the reason why, as several authors $(8,11-14)$ already stated, the additional pleurodesis (chemical or surgical) to bullectomy is strongly recommended. In fact, pleurodesis does not eliminate the formation of neogenetic bullae but inhibits their rupture, reducing the rate of postoperative recurrence.

The debate about the better method of pleurodesis is still ongoing.

Although a recent meta-analysis (14) confirmed the safety and superiority of chemical pleurodesis (with talc as the most used agent) in term of effectiveness [recurrence rate of PSP: $1.2 \%$ vs. $4 \%$ after mechanical one; pooled odds ratio $(\mathrm{OR})=3.00 ; 95 \%$ confidence interval $(\mathrm{CI}), 1.59-5.67$; $\mathrm{P}=0.0007 ; \mathrm{I}^{2}=19 \%$ ] and shorter hospital stay [pooled mean difference $(M D)=0.42$ days; 95\% CI, 0.12-0.72; $\left.\mathrm{P}=0.005 ; \mathrm{I}^{2}=0 \%\right]$, some surgeons are still concerned about administering this inert material to young patients (1).

In our experience of more than 35 years at our Department of General Thoracic Surgery, the main and almost exclusive method used for pleurodesis associated to bullectomy for PSP is selective talc poudrage [with $1 \mathrm{~g}$ of medical, purified, graded $(>25 \mu \mathrm{m})$ talc] on lung apex in VATS. We only switched from Triportal-VATS to the less invasive uniportal-VATS (15) as surgical approach, in 2016, but on pleurodesis issue we have always believed that talc poudrage is superior to mechanical pleurodesis or other sclerosant agents in terms of efficacy, less complications and lower hospital stay. In fact, in our series the risk of PNX recurrence after bullectomy and talc poudrage in VATS is less than $1.5 \%$ (in line with other studies in literature), the risk of re-operation for bleeding is null (compared to mechanical pleurodesis) and post-operative hospital stay is on average 4 days.

Furthermore, we prefer selective talc poudrage to pleurectomy because, above all in young people, the possibility of future lung surgery (for any reason, neoplastic or others) is reasonable and presumably it is less complicated and safer enter the pleural cavity after chemical pleurodesis (where the extrapleural way is still available) than after pleurectomy. Moreover, we don't believe that the use of modern medical, purified (without asbestos) talc in pleural cavity could be implicated in carcinogenetic processes of the lung or the pleura, since there is no evidence in literature.

About that, in 2019, a systematic review by Baiu and coworkers (16) analyzed the role of talc in the scientific literature after the year 2000, focusing on its mechanism of action, efficacy and side effects compared to other sclerosant agents.

The authors (16) stated that the modern medical talc, produced after the 1970s, is safe because purified (asbestosfree) so concerns about the development of cancer in pleural space is currently unfounded. Furthermore, it is graded (that means that the mean particle size is large, between 25 and $50 \mu \mathrm{m}$ ) and there is no evidence of major side effects, like ARDS, when large particles are used [at the dosage of maximum 4-5 grams in a $70 \mathrm{Kg}$ adult, in agreement with American Thoracic Society 2000 Consensus recommendations (17)], but only fever and chest pain like common reactions. Talc pleurodesis is more effective than pleurectomy or mechanical pleural abrasion, with recurrence rates of $0.4-1.8 \%$. Although talc seems to be a safe, effective, accessible and inexpensive option, the authors reminded that other alternatives do exist, like silver nitrate, tetracycline (no longer available for pleurodesis in some countries, like in USA), bleomycin, iodopovidone, autologous blood etc., but they are not as well studied in terms of dosage and effectiveness.

Therefore, Baiu et al. (16) concluded that medical, purified, graded talc currently is the gold standard agent for pleurodesis.

On the other hand, in their interesting study, Dżeljilji and coworkers (5) performed almost a complete removal of parietal pleura in all patients as pleurodesis method.

Authors' surgical methods and results (5) confirmed the indications summarized by the review of the Italian Pneumothorax working group on the treatment of PSP (1), both for the bullectomy performed in case of Vanderschueren's stage III and IV and for the type of surgical pleural symphysis employed.

However, evaluating risks (like postoperative bleeding) and benefits of the procedure, the authors also wondered about the better method for pleuro-pulmonary symphysis.

We highly agree with them in claiming the necessity of new researches and randomized trials to accurately assess the efficacy of the available methods and better investigate factors correlated with the effectiveness of the surgical treatments of PSP.

\section{Acknowledgments}

Funding: None. 


\section{Footnote}

Conflicts of Interest: All authors have completed the ICMJE uniform disclosure form (available at http://dx.doi. org/10.21037/jtd.2020.03.40). The authors have no conflicts of interest to declare.

Ethical Statement: The authors are accountable for all aspects of the work in ensuring that questions related to the accuracy or integrity of any part of the work are appropriately investigated and resolved.

Open Access Statement: This is an Open Access article distributed in accordance with the Creative Commons Attribution-NonCommercial-NoDerivs 4.0 International License (CC BY-NC-ND 4.0), which permits the noncommercial replication and distribution of the article with the strict proviso that no changes or edits are made and the original work is properly cited (including links to both the formal publication through the relevant DOI and the license). See: https://creativecommons.org/licenses/by-nc-nd/4.0/.

\section{References}

1. Mendogni P, Vannucci J, Ghisalberti M, et al. Epidemiology and management of primary spontaneous pneumothorax: a systematic review. Interact Cardiovasc Thorac Surg 2020;30:337-45.

2. Schramel FM, Postmus PE, Vanderschueren RG. Current aspects of spontaneous pneumothorax. Eur Respir J 1997;10:1372-9.

3. Noppen M, Dekeukeleire T, Hanon S, et al. Fluoresceinenhanced autofluorescence thoracoscopy in patients with primary spontaneous pneumothorax and normal subjects. Am J Respir Crit Care Med 2006;174:26-30.

4. Smit HJ, Golding RP, Schramel FM, et al. Lung density measurements in spontaneous pneumothorax demonstrate airtrapping. Chest 2004;125:2083-90.

5. Dżeljilji A, Karuś K, Kierach A, et al. Efficacy and safety of pleurectomy and wedge resection versus simple pleurectomy in patients with primary spontaneous pneumothorax. J Thorac Dis 2019;11:5502-8.

6. Loubani M, Lynch V. Video assisted thoracoscopic bullectomy and acromycin pleurodesis: an effective treatment for spontaneous pneumothorax. Respir Med 2000;94:888-90.

7. Sahn SA, Heffner JE. Spontaneous pneumothorax. N Engl J Med 2000;342:868-74.
8. Onuki T, Kawamura T, Kawabata S, et al. Neo-generation of neogenetic bullae after surgery for spontaneous pneumothorax in young adults: a prospective study. $\mathrm{J}$ Cardiothorac Surg 2019;14:20.

9. Choi SY, Kim DY, Suh JH, et al. New bullae formation in the staple line increases the risk of recurrent pneumothorax following video-assisted thoracoscopic surgery bullectomy for primary spontaneous pneumothorax. J Thorac Dis 2018;10:4287-92.

10. Nakayama T, Takahashi $Y$, Uehara H, et al. Outcome and risk factors of recurrence after thoracoscopic bullectomy in young adults with primary spontaneous pneumothorax. Surg Today 2017;47:859-64.

11. Hallifax RJ, Yousuf A, Jones HE, et al. Effectiveness of chemical pleurodesis in spontaneous pneumothorax recurrence prevention: a systematic review. Thorax 2017;72:1121-31.

12. Mithiran H, Leow L, Ong K, et al. Video-Assisted Thoracic Surgery (VATS) Talc Pleurodesis Versus Pleurectomy for Primary Spontaneous Pneumothorax: A Large Single-Centre Study with No Conversion. World J Surg 2019;43:2099-105.

13. Horio H, Nomori H, Kobayashi R, et al. Impact of additional pleurodesis in video-assisted thoracoscopic bullectomy for primary spontaneous pneumothorax. Surg Endosc 2002;16:630-4.

14. Sim SKR, Nah SA, Loh AHP, et al. Mechanical versus Chemical Pleurodesis after Bullectomy for Primary Spontaneous Pneumothorax: A Systemic Review and MetaAnalysis. Eur J Pediatr Surg 2019. [Epub ahead of print].

15. Nachira D, Ismail $M$, Meacci E, et al. Uniportal vs. triportal video-assisted thoracic surgery in the treatment of primary pneumothorax-a propensity matched bicentric study. J Thorac Dis 2018;10:S3712-9.

16. Baiu I, Yevudza E, Shrager JB. Talc Pleurodesis: a Medical, Medicolegal, and Socioeconomic Review. Ann Thorac Surg 2020;109:1294-301.

17. American Thoracic Society. Management of malignant pleural effusions. Am J Respir Crit Care Med 2000;162:1987-2001.

Cite this article as: Nachira D, Meacci E, Congedo MT, Pogliani L, Chiappetta M, Vita ML, Margaritora S. Surgical treatment of primary spontaneous pneumothorax: what is better to do? J Thorac Dis 2020;12(4):1274-1276. doi: 10.21037/ jtd.2020.03.40 